\title{
Composição química do óleo essencial e avaliação da atividade antimicrobiana do óleo essencial, extrato etanólico bruto e frações das folhas de Spiranthera odoratissima A. St.-Hil.
}

CHAIBUB, B.A. ${ }^{1}$; OLIVEIRA, T.B..'; FIUZA, T.S. ${ }^{2}$; BARA, M.T.F.'; TRESVENZOL, L.M.F.'; PAULA, J.R. ${ }^{1}$ ${ }^{1}$ Faculdade de Farmácia, Universidade Federal de Goiás, Caixa Postal 131, CEP: 74001-970, Goiânia-Brasil 2Instituto de Ciências Biológicas, Universidade Federal de Goiás, Caixa Postal 131, CEP: 74001-970, Goiânia-Brasil

\begin{abstract}
RESUMO: A Spiranthera odoratissima A. St.-Hil (manacá) é utilizada popularmente como depurativo do sangue, nas afecções renais e hepáticas (chá das folhas) para dores musculares, de estômago, de cabeça, e disfunções hepáticas (chá das raízes). O objetivo desse trabalho foi avaliar a composição química do óleo essencial e a atividade antimicrobiana do óleo essencial, do extrato etanólico bruto e frações obtidos das folhas de S. odoratissima contra bactérias Gram positivas e negativas, e Candida albicans. O extrato bruto das folhas foi obtido por maceração seguido de concentração em rotaevaporador e as frações por partição em coluna filtrante. O pó das folhas foi submetido à hidrodestilação em aparelho de Clevenger e o óleo essencial obtido foi analisado por CG/EM. A atividade antimicrobiana foi avaliada pelo método da diluição em ágar para determinar a concentração inibitória mínima (CIM). Os constituintes majoritários do óleo essencial foram $\beta$-cariofileno (20,64\%), $\gamma$-muuroleno (17,70\%), biciclogermacreno $(14,73 \%)$, e $\delta$-cadineno $(13,40 \%)$. No estudo da atividade antimicrobiana de $S$. odoratissima, os principais resultados foram obtidos contra Staphylococus epidermidis (extrato etanólico bruto, CIM de 0,098 $\mathrm{mg} / \mathrm{mL}$ ), C. albicans (fração hexano, CIM de 0,049 mg/mL), Bacillus cereus (diclorometano, CIM de 0,098 mg/mL), Micrococcus roseus (fração acetato de etila, CIM 0,049 mg/mL), e M. roseus, Micrococus luteus, B. cereus e C. albicans (fração metanol, CIM de 0,391 mg/mL).
\end{abstract}

Palavras-chave: plantas medicinais, manacá, Rutaceae, Cerrado, $\beta$-cariofileno.

ABSTRACT: Chemical composition of the essential oil and evaluation of the antimicrobial activity of essential oil, crude ethanol extract and fractions of Spiranthera odoratissima A. St.-Hil. leaves. Spiranthera odoratissima ("manacá") has been popularly used as a blood cleanser, for liver and kidney diseases (tea from the leaves), as well as for muscle and stomach pains, headache and liver disorders (tea from the roots). The aim of this study was to evaluate the chemical composition of the essential oil and the antimicrobial activity of essential oil, crude ethanol extract and fractions of S. odoratissima leaves against Gram-positive and negative bacteria and Candida albicans. The crude extract of the leaves was obtained by maceration and was concentrated in a rotavapor, while the fractions were obtained by partition on column filter. The powdered leaves underwent hydrodistillation in a Clevenger apparatus and the obtained essential oil was analyzed by GC/MS. The antimicrobial activity was evaluated by using the agar dilution method for determining the minimum inhibitory concentration (MIC). The major constituents of the essential oil were $\beta$-caryophyllene $(20.64 \%), \gamma$-muurolene $(17.70 \%)$, bicyclogermacrene $(14.73 \%)$ and $\delta$-cadinene $(13.40 \%)$. The main results for $S$. odoratissima antimicrobial activity were found against Staphylococcus epidermidis (crude ethanol extract, MIC of $0.098 \mathrm{mg} / \mathrm{mL}$ ), C. albicans (hexane fraction, MIC of $0.049 \mathrm{mg} / \mathrm{mL}$ ), Bacillus cereus (dichloromethane fraction, MIC of $0.098 \mathrm{mg} / \mathrm{mL}$ ), Micrococcus roseus (ethyl acetate fraction, $\mathrm{MIC}$ of $0.049 \mathrm{mg} / \mathrm{mL}$ ) and M. roseus, Micrococcus luteus, B. cereus and C. albicans (methanol fraction, MIC of $0.391 \mathrm{mg} / \mathrm{mL}$ ).

Key words: medicinal plants, "manacá”, Rutaceae, Cerrado, $\beta$-caryophyllene.

Recebido para publicação em 06/11/2010

Aceito para publicação em 23/07/2012

Rev. Bras. PI. Med., Campinas, v.15, n.2, p.225-229, 2013. 


\section{INTRODUÇÃO}

A Spiranthera odoratissima A. ST.-Hil. (Rutaceae), conhecida popularmente como manacá, é um subarbusto encontrado no Cerrado. O chá de suas folhas é utilizado popularmente como depurativo do sangue e nas afecções renais e hepáticas (Salles et al., 1997), enquanto o chá das raízes é empregado para dores estomacais, musculares e de cabeça e nas disfunções hepáticas (Silva, 1998). Em Goiás, as raízes do manacá são utilizadas em forma de chá ou tintura para o tratamento do reumatismo (Paula et al., 1999; Tresvenzol et al., 2006).

Dados da literatura relatam que a fração aquosa do extrato etanólico das folhas de $S$. odoratissima apresentou atividade anti-inflamatória e analgésica (Matos et al., 2003), enquanto o extrato etanólico bruto das raízes mostrou atividade anti-inflamatória e depressora do sistema nervoso central (Matos et al., 2004). Barbosa et al. (2012) sugerem que o efeito analgésico das folhas de $S$. odoratissima pode ser, em parte, atribuído à ação anti-inflamatória produzida pela inibição da atividade da fosfolipase $A_{2}$. Galdino et al. (2012) relataram que o óleo essencial das folhas de S. odoratissima apresentou atividade ansiolítica em camundongos.

Em relação aos estudos fitoquímicos, Terezan et al. (2010) isolaram dos ramos da S. odoratissima os alcalóides furoquinolínicos (dictamina, g-fagarina e esquimianina), 2-arilquinolin4-ona (2-fenil-1-metilquinolin-4-ona) e os limonóides (ácido limonéxico, limonina). Enquanto Ribeiro et al. (2005) isolaram das raízes onze substâncias sendo dois limonóides, três alcaloides furoquinolínicos, três alcaloides $\beta$-indoloquinazolínicos, além da cumarina aurapteno e do $\beta$-sitosterol.

Os objetivos deste trabalho foram: avaliar a composição química do óleo essencial e as atividades antimicrobianas do óleo essencial, extrato etanólico bruto e frações (hexano, acetato de etila, diclorometano e metanol) das folhas de Spiranthera odoratissima, coletadas em Goiás.

\section{MATERIAIS E MÉTODOS}

\section{Material botânico}

As folhas de $S$. odoratissima foram coletadas no município de Senador Canedo/GO (16²4'45,2"Sul, 4907'06,8"Oeste, a 762m de altitude), em dezembro de 2007. O material botânico foi identificado pelo Prof. Dr. José Realino de Paula da Universidade Federal de Goiás e uma exsicata depositada no herbário desta instituição sob registro UFG/30275.

As folhas foram dessecadas à temperatura ambiente e trituradas em moinho de facas até obtenção de pó (400-500 mesh).

\section{Preparação do óleo essencial, extrato bruto e frações}

Para a extração do óleo essencial, 150 $\mathrm{g}$ do material botânico pulverizado foi submetido à hidrodestilação em aparelho de Clevenger modificado, por 3 horas.

O extrato etanólico bruto (EE) foi obtido por maceração de $500 \mathrm{~g}$ do pó das folhas em etanol 95\% na proporção de 1:5, seguido de concentração em rotaevaporador a 40ÚC. Posteriormente, $50 \mathrm{~g}$ do EE foram misturados com celulose microcristalina em quantidade suficiente para a incorporação total do extrato. A mistura foi acondicionada em uma coluna cromatográfica com $3 \mathrm{~cm}$ de diâmetro e $40 \mathrm{~cm}$ de comprimento, resultando em $29,5 \mathrm{~cm}$ de celulose (fase estacionária). Em seguida foi eluída ( $3 \times 100 \mathrm{~mL}$ ), sucessivamente, com hexano (PA), diclorometano (PA), acetato de etila (PA) e metanol (PA), sendo as frações concentradas em rotaevaporador a $40^{\circ} \mathrm{C}$ (Nascimento, Meneses \& Lacerda, 2010).

\section{Avaliação da atividade antimicrobiana Microrganismos}

Para avaliar a atividade antimicrobiana foram utilizados os seguintes microrganismos: Bacillus cereus ATCC 14576, Micrococcus luteus ATCC 9341, Micrococcus roseus ATCC 1740, Staphylococcus aureus ATCC 25923, Staphylococcus aureus ATCC 6538, Staphylococcus epidermidis ATCC 12229, Serratia marcences ATCC 14756, Enterobacter cloacae HMA/FTA 502, Enterobacter aerogenes ATCC 13048, Escherichia coli ATCC 8739, Escherichia coli ATCC 11229, Bacillus subtilis ATCC 6633, Pseudomonas aeruginosa ATCC 27483, Pseudomonas aeruginosa ATCC 9027, Candida albicans NTC 2010. Os microrganismos foram fornecidos pelo Laboratório de Bacteriologia do Instituto de Patologia Tropical e Saúde Pública (IPTSP) da Universidade Federal de Goiás.

Para a ativação das respectivas culturas procedeu-se o repique em Caldo Casoy, incubandose por 24 horas a $37^{\circ} \mathrm{C}$. Após a turvação, indicativa de crescimento microbiano, foi realizado um novo repique em ágar Casoy inclinado, seguido de incubação a $37^{\circ} \mathrm{C}$ por 24 horas.

\section{Concentração Inibitória Mínima (CIM)}

A determinação da concentração inibitória mínima (CIM) foi realizada pelo método da diluição em placa, conforme recomendação do NCCLS (2003).

Para a preparação das placas, $500 \mathrm{mg}$ do extrato etanólico bruto e do óleo essencial e 250 $\mathrm{mg}$ das frações hexano, diclorometano, acetato de etila e metanol foram solubilizados em $2 \mathrm{ml}$ de dimetilsulfóxido (DMSO) e submetidos a diluições 
seriadas $1: 2$ por mais 8 tubos. Em seguida foi adicionado a cada tubo $19 \mathrm{~mL}$ de ágar Muller-Hinton a $50^{\circ} \mathrm{C}$. Os tubos foram homogeneizados com o auxilio de um vórtex e seu conteúdo adicionado a placas de Petri de forma a se obter concentrações variando de $12,50 \mathrm{mg} / \mathrm{mL}$ a $0,098 \mathrm{mg} / \mathrm{mL}$ para o extrato etanólico bruto e o óleo essencial e de $6,25 \mathrm{mg} / \mathrm{mL}$ a 0,049 $\mathrm{mg} / \mathrm{mL}$ para as frações. Placas contendo DMSO e somente o meio de cultura, preparadas nas mesmas condições, foram utilizadas como controles.

As suspensões dos microrganismos foram preparadas em solução salina estéril $0,9 \%$, sendo a turvação ajustada até obtenção de uma turbidez equivalente a metade da escala 1,0 de MacFarland (NCCLS, 2003).

Os inóculos microbianos foram aplicados nas placas com o auxílio do inoculador de Steers (Steers et al., 1959) e as placas incubadas a $37 u ́ C$ por 24 horas (bactérias) e 48 horas (fungo). Foi considerada CIM a menor concentração do extrato etanólico bruto, das frações e do óleo essencial que inibiu o desenvolvimento das bactérias e do fungo. $\mathrm{O}$ experimento foi realizado em duplicata.

\section{Análise da composição química do óleo essencial \\ O óleo essencial foi analisado por} cromatografia gasosa (CG) acoplada à espectrometria de massas (EM) em aparelho SHIMADZU QP5050A. Foi utilizada uma coluna capilar de sílica fundida

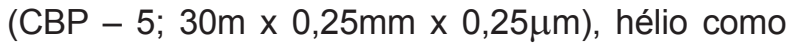
gás de arraste com fluxo $1 \mathrm{~mL} / \mathrm{min}$, aquecimento com temperatura programada $\left(60^{\circ} \mathrm{C} / 2 \mathrm{~min} ; 60^{\circ}-240^{\circ} \mathrm{C}\right.$ a $3^{\circ} \mathrm{C} / \mathrm{min} ; \quad 280^{\circ} \mathrm{C}$ a $10^{\circ} \mathrm{C} / \mathrm{min}$ e $280^{\circ} \mathrm{C} / 10 \mathrm{~min}$ ) e energia de ionização de $70 \mathrm{eV}$. O volume de amostra injetada, após diluição em $\mathrm{CH}_{2} \mathrm{Cl}_{2}$, foi de $1 \mu \mathrm{L}$ na proporção de 1:5. Os componentes químicos do óleo essencial foram identificados com base no tempo de retenção (considerando-se uma série homóloga de n-alcanos $\mathrm{C}_{9}-\mathrm{C}_{26}$ ), índice de Kovats, bem como, por comparação do padrão de fragmentação próprio de cada componente com espectros de massa descritos na literatura (Adams, 2007).

\section{RESULTADOS}

Os rendimentos das folhas de $S$. odoratissima foram: Óleo essencial, 2,3\%; extrato bruto, $32,5 \%$; fração hexano, 17,9\%; fração diclorometano,1,5\%; fração acetato de etila, 3,1\%; e fração metanol, $77,5 \%$.

No óleo essencial das folhas de $S$. odoratissima foram identificadas 25 substâncias, sendo $73,84 \%$ hidrocarbonetos sesquiterpênicos e $7,13 \%$ sesquiterpenos oxigenados. Os componentes majoritários foram: $\beta$-cariofileno $(20,64 \%)$, $\gamma$-muuroleno $(17,7 \%)$, biciclogermacreno $(14,73 \%)$ e $\delta$-cadineno (13,40\%) (Tabela 1).

No estudo da atividade antimicrobiana do óleo essencial das folhas de S. odoratissima obtevese CIM de 0,195 a $3,125 \mathrm{mg} / \mathrm{mL}$ para as bactérias Gram positivas, CIM de 6,250 a $12,50 \mathrm{mg} / \mathrm{mL}$ para as bactérias Gram negativas e CIM de $1,562 \mathrm{mg} / \mathrm{mL}$ para o fungo $C$. albicans.

Os melhores resultados da atividade antimicrobiana foram obtidos contra $S$. epidermidis (extrato etanólico bruto, CIM de 0,098mg $/ \mathrm{mL}$ ), C. albicans (fração hexano, CIM de $0,049 \mathrm{mg} / \mathrm{mL}$ e fração acetato de etila, CIM de $0,098 \mathrm{mg} / \mathrm{mL}$ ), $B$. cereus (fração diclorometano, CIM de $0,098 \mathrm{mg} / \mathrm{mL}$ ), M. roseus (fração acetato de etila, CIM 0,049mg/ $\mathrm{mL}$ ) (Tabela 2).

TABELA 1. Percentagem dos constituintes químicos do óleo essencial das folhas de S. odoratissima.

\begin{tabular}{lcc}
\hline Constituinte & IR & $\begin{array}{c}\text { Percentagem } \\
\text { (\%) }\end{array}$ \\
\hline$\delta$-elemeno & & \multicolumn{1}{c}{0,93} \\
$\alpha$-cubebeno & 1333 & 1,09 \\
$\alpha$-copaeno & 1346 & 1,09 \\
$\beta$-cubebeno & 1372 & 2,05 \\
$\beta$-elemeno & 1386 & 0,49 \\
$\beta$-cariofileno & 1393 & 0,61 \\
$\beta$-copaeno & 1416 & 20,64 \\
$\alpha$-trans-bergamoteno & 1425 & 0,60 \\
Aromadendreno & 1431 & 0,53 \\
$\alpha$-humuleno & 1435 & 1,20 \\
9-epi-E-cariofileno & 1449 & 2,79 \\
trans-cadina-1(6),4-dieno & 1456 & 1,35 \\
$\gamma$-gurjuneno & 1469 & 0,47 \\
$\gamma$-muuroleno & 1472 & 2,91 \\
$\beta$-selineno & 1477 & 17,70 \\
trans-cadina-1(6),4-dieno & 1482 & 0,85 \\
Biciclogermacreno & 1487 & 0,97 \\
$\alpha$-muuroleno & 1492 & 14,73 \\
$\gamma$-cadineno & 1495 & 2,02 \\
$\delta$-cadineno & 1509 & 4,59 \\
trans-cadina-1,4-dieno & 1519 & 13,40 \\
$\alpha$-cadineno & 1527 & 0,34 \\
$\beta$-germacreno & 1533 & 0,55 \\
epatulenol & 1552 & 1,35 \\
cubenol & 1572 & 0,68 \\
\hline Hidrocarbonetos sesquiterpênicos & 1649 & 3,12 \\
\hline Sesquiterpenos oxigenados & & 73,84 \\
Outros & & 7,13 \\
\hline Total & & 95,96 \\
\hline & & \\
\hline & & \\
\hline
\end{tabular}


TABELA 2. Concentração Inibitória Mínima do óleo essencial, do extrato etanólico bruto e das frações hexano, diclorometano acetato de etila e metanol das folhas da $S$. odoratissima $(\mathrm{mg} / \mathrm{mL})$.

\begin{tabular}{lcccccc}
\hline Microrgansimos & $\begin{array}{c}\text { Óleo } \\
\text { essencial }\end{array}$ & $\begin{array}{c}\text { Extrato } \\
\text { bruto }\end{array}$ & $\begin{array}{c}\text { Fração } \\
\text { hexano }\end{array}$ & $\begin{array}{c}\text { Fração } \\
\text { dicloro }\end{array}$ & $\begin{array}{c}\text { Fração } \\
\text { a. Etila }\end{array}$ & $\begin{array}{c}\text { Fração } \\
\text { metanol }\end{array}$ \\
\hline Bactérias Gram positivas & & & & & & \\
Staphylococcus aureus ATCC 6538) & 3,125 & 3,125 & $>6,250$ & 0,391 & 0,391 & 1,562 \\
Staphylococcus aureus ATCC 25923 & 3,125 & 3,125 & $>6,250$ & 0,195 & 0,391 & 1,562 \\
Staphylococcus epidermidis ATCC 12228 & 3,125 & 0,098 & $>6,250$ & 3,125 & 0,781 & 0,781 \\
Micrococcus roseus 1740 & 0,195 & 0,391 & 0,195 & 0,195 & 0,049 & 0,391 \\
Micrococcus luteus ATCC 9341 & 1,562 & 1,562 & 0,195 & 0,195 & 0,391 & 0,391 \\
Bactérias Grampositivas esporuladas & & & & & & \\
Bacillus cereus ATCC 14579 & 3,125 & 0,781 & 0,195 & 0,098 & 0,195 & 0,391 \\
Bacillus subtilis ATCC 6633 & 3,125 & 1,562 & $>6,25$ & 0,391 & 0,391 & 0,781 \\
Bactérias Gram negativas & & & & & & \\
Enterobacter cloacae HMA/FT 502 & 12,5 & 3,125 & $>6,250$ & $>6,250$ & 3,125 & 1,562 \\
Enterobacter aerogenes (ATCC 13048) & 12,5 & 3,125 & $>6,250$ & $>6,250$ & 3,125 & 1,562 \\
Escherichia coli ATCC 11229 & 12,5 & 3,125 & $>6,250$ & $>6,250$ & 3,125 & 3,125 \\
Escherichia coli ATCC 8739 & 12,5 & 12,5 & $>6,250$ & $>6,250$ & 3,125 & 3,125 \\
Pseudomonas aeruginosa 27483 & 6,25 & 1,562 & $>6,25$ & $>6,25$ & 0,391 & 0,781 \\
Pseudomonas aeruginosa ATCC 9027 & 6,25 & 1,562 & $>6,25$ & $>6,25$ & 0,391 & 0,781 \\
Serratia marcescens ATCC 14756 & 6,25 & 3,125 & $>6,250$ & 3,125 & 3,125 & 1,562 \\
Fungo & & & & & & 0,391 \\
Candida albicans NTC 2010 & 1,562 & 0,781 & 0,049 & 0,195 & 0,098 & 0,39 \\
\hline
\end{tabular}

\section{DISCUSSÃO}

O óleo essencial obtido das folhas de S. odoratissima apresentou grande quantidade de hidrocarbonetos sesquiterpênicos, entre os quais se destacam: $\beta$-cariofileno, $\gamma$-muuroleno, biciclogermacreno e $\delta$-cadineno, perfazendo $66,47 \%$ da composição total do óleo. Estes compostos também foram encontrados como majoritários nos óleos essenciais de outras espécies da família Rutaceae, como Haplophyllum linifolium (biciclogermacreno e $\beta$-cariofileno) (Iñigo et al., 2002) e em Acronychia pedunculata ( $\beta$-cariofileno) (Lesueur et al., 2008).

O $\beta$-cariofileno também foi identificado como um dos componentes majoritário nos óleos essenciais de: Galeopsis bífida (22\%) (Olenikov, Dudareva \& Tankhaeva, 2010); Vernonia remotiflora $(42,2 \%)$ e Vernonia brasiliana $(36,7 \%)$ (Maia et al., 2010); Annona foetida (14,19\%) (Costa et al., 2009). Enquanto o biciclogermacreno foi identificado como componente majoritário no óleo essencial de Annona foetida (35,12\%) (Costa et al., 2009).

De acordo com Aligianis et al. (2001), utilizando o método da diluição em caldo, a CIM $\leq 0,5 \mathrm{mg} / \mathrm{mL}$ corresponde a uma forte inibição antimicrobiana, CIM entre $0,6 \mathrm{mg} / \mathrm{mL}$ a $1,5 \mathrm{mg} / \mathrm{mL}$ a inibição moderada e CIM>1,6 mg/mL a uma inibição fraca. Considerando esses parâmetros verificou-se que o óleo essencial de S. odoratissima apresentou fraca inibição contra todos os microrganismos testados. O extrato etanólico bruto e as frações apresentaram inibições variadas contra bactérias Gram positivas e o fungo $C$. albicans e pouca ou nenhuma atividade contra as bactérias Gram negativas. Fortes inibições foram obtidas com o extrato etanólico bruto contra $S$. epidermides e $B$. cereus e, com a fração hexano contra M. luteus e $B$. cereus. As frações acetato de etila e diclorometano apresentaram inibições fortes ou moderadas contra a maior parte das bactérias Gram positivas. A fração acetato de etila se destacou pela forte inibição contra duas cepas de $P$. aeruginosa. Tanto o extrato etanólico bruto quanto as frações apresentaram boa atividade contra o fungo $C$. albicans.

A atividade antimicrobiana dos óleos essenciais e de seus constituintes isolados tem sido objeto de muitas pesquisas nos últimos anos e está relacionada com as características químicas, grupos funcionais e estereoquímica dos constituintes e os compostos oxigenados presentes nos óleos essenciais, em particular aqueles com estrutura fenólica (carvacrol, eugenol, timol), terpenóides alifáticos com grupamento éster (acetato de geranila), álcool (linalol) ou aldeído (cinamaldeído) 
se destacam por apresentarem um bom potencial antimicrobiano (Henriques, Simões-Pires \& Apel, 2009).

O óleo essencial das folhas S. odoratissima apresentou como compostos majoritários hidrocarbonetos sesquiterpênicos e apenas 7,13\% de sesquiterpenos oxigenados. Considerando o trabalho de Henriques, Simões-Pires \& Apel (2009), isso pode justificar a fraca atividade antimicrobiana do óleo essencial dessa espécie.

Em relação à atividade antimicrobiana de S. odoratissima, Silva et al. (2010) verificaram que os extratos hexânico e metanólico das folhas, caule e rizoma, bem como, o extrato clorofórmico das folhas, coletadas em Mucugê-Ba não apresentaram atividade frente aos microrganismos testados. Resultados semelhantes foram obtidos no presente estudo para bactérias Gram negativas e para algumas Gram positivas. Para as bactérias Gram positivas $S$. aureus, $M$ luteus e o fungo $C$. albicans, o resultado foi divergente em relação ao trabalho de Silva et al. (2010). Isso pode ser atribuído a variações na composição química dos extratos (obtidos por metodologias diferentes), bem como, por diferenças na metodologia e nas cepas dos microrganismos utilizadas.

Concluiu-se que as folhas de S. odoratissima apresentaram um alto teor de óleos essenciais, tendo como componentes majoritários o $\beta$-cariofileno, $\gamma$-muuroleno, biciclogermacreno e $\delta$-cadineno, e que o óleo e os extratos das folhas dessa espécie apresentaram atividade antimicrobiana de moderada a fraca contra alguns microrganismos.

\section{AGRADECIMENTOS}

Os autores agradecem à FAPEG/GO - Processo no 200810267000065, pelo apoio financeiro.

\section{REFERÊNCIA}

ADAMS, R.P. Identification of essential oil components by gas chromatography mass spectrometry. 4. ed. Carol Stream: Allured Publishing Corporation, 2007. 469p.

ALIGIANIS, N. et al. Composition and antimicrobial activity of the essential oil of two Origanum species. Journal of Agricultural and Food Chemistry, v.49, p.4168-70, 2001.

BARBOSA D.B.M. et al. Mechanism involved in the antiinflammatory effect of Spiranthera odoratissima (Manacá). Brazilian Journal of Pharmacognosy, v.22, n.1, p.13743, 2012.

COSTA, E.V. Antimicrobial and antileishmanial activity of essential oil from the leaves of Annona foetida (Annonaceae). Quimica Nova, v. 32, n.1, p. 78-81, 2009 GALDINO, P.M. et al. The anxiolytic-like effect of an essential oil derived from Spiranthera odoratissimaA. St.-Hil. leaves and its major componente, beta-caryophyllene, in male mice. Progress in Neuro-Psychopharmacology \&
Biological Psychiatry, v. 38, n. 2, p.276-84, 2012.

HENRIQUES, A.T. et al. Óleos essenciais: importância e perspectivas terapêuticas. In: YUNES, R.A.; CECHIMEL FILHO, V. (orgs.). Química de produtos naturais, novos fármacos e a moderna farmacognosia. 2.ed. Itajaí: Universidade do Vale do Itajaí, 2009. p.219-256.

IÑIGO, A. et al. Essential oil composition from the aerial parts of Haplophyllum linifolium (L.) G. Don fil. Botanica Complutensis, v.26, p.79-83, 2002.

LESUEUR, D. et al. Composition and antimicrobial activity of the essential oil of Acronychia pedunculata (L.) Miq. from Vietnam. Natural Product Research, v.22, n.5, p.393-8, 2008.

MAIA, A.I.V. et al. Óleos essenciais das folhas de Vernonia remotiflora e Vernonia brasiliana: composição química e atividade biológica. Química Nova, v.33, p.584-6, n.3, 2010.

MATOS, L.G. et al. Atividade analgésica e/ou antiinflamatória da fração aquosa do extrato etanólico das folhas de Spiranthera odoratissima A. St. Hillaire (manacá). Revista Brasileira de Farmacognosia, v.13, p.15-16, 2003.

MATOS, L.G. et al. Analgesic and anti-inflamatory activity of the ethanolic extract from Spiranthera odoratissima A. St. Hillaire (manacá) roots. Phytotherapy Research, v.18, n.12, p.963-6, 2004.

NASCIMENTO, G.C.; MENEZES, A.C.S. \& LACERDA, E.P.P. Identificação do flavonóide 7,4'-dimetoxi-quercetina3-O-B-D-licopiranosídeo e avaliação da atividade antitumoral dos frutos. Revista Processos Químicos, v.5, n.10, p.44-55, 2011.

NCCLS. National Committee for Clinical Laboratory Standards. Methods for dilution antimicrobial susceptibility tests for bacteria that grow aerobically. Approved standard. 2003. p.1-47.

OLENNIKOV, D. N. DUDAREVA, L. V. \& TANKHAEVA L. M.. Chemical composition of essential oils from Galeopsis bifida and Phlomoides tuberosa. Chemistry of Natural Compounds, v.46, n.2, p. 316-18, 2010.

PAULA, J.R. et al. Contribuição ao Estudo Farmacognóstico de Spiranthera odoratissima A. St. Hil. In: JORNADA PAULISTADE PLANTAS MEDICINAIS, 4., 1999, Ribeirão Preto. Livro de Resumos. Ribeirão Preto: UNAERP, 1999. p. 84.

RIBEIRO, T.A.N. et al. Limoinides from Spiranthera odoratissima St. Hil. Journal of the Brazilian Chemical Society, v.16, n.16, p.1347-52, 2005.

SALLES, A.H. et al. Horto Medicinal do Cerrado. 2.ed. Brasília: Jardim Botânico de Brasília, 1997. 33p.

SILVA, S.R. Plantas do Cerrado utilizadas pelas comunidades da região do Grande Sertão Veredas. 1. ed. Brasília: Funatura, 1998. 109p.

SILVA, et al. Avaliação da atividade antimicrobiana de duas espécies de Rutaceae do Nordeste Brasileiro. Revista Brasileira de Farmacognosia, v. 20, n.3, p.355-60, 2010.

STEERS, E. et al. An inocula replicating apparatus for continue testing of bacterial susceptibility to antibiotics. Antibiotics and Chemotherapy, v.9, p.307-11, 1959.

TEREZAN, A.P. Activities of extracts and compounds from Spiranthera odoratissima St. Hil. (Rutaceae) in leaf-cutting ants and their symbiotic fungus. Journal of Brazilian Chemical Society, v. 21, n.5, p.882-6, 2010.

TRESVENZOL, L.M. et al. Estudo sobre o comércio informal de plantas medicinais em Goiânia e cidades vizinhas. Revista Eletrônica de Farmácia, v.3, p.23-8, 2006.

Rev. Bras. PI. Med., Campinas, v.15, n.2, p.225-229, 2013. 